\title{
Policing Directions: A Systematic Review on the Efficacy of Quantitative Police Presence
}

Philipp M. Dau ${ }^{1}$, Christophe Vandeviver ${ }^{1,2}$, Maite Dewinter ${ }^{3}$, Frank Witlox ${ }^{3,4,5}$, Tom Vander Beken $^{1}$

${ }^{1}$ Department of Criminology, Criminal Law and Social Law, Ghent University, Universiteitstraat 4, Ghent 9000, Belgium

${ }^{2}$ Research Foundation-Flanders (FWO), Egmontstraat 5, Brussels 1000, Belgium

${ }^{3}$ Department of Geography, Ghent University, Krijgslaan 281 S8, Ghent 9000, Belgium

${ }^{4}$ Department of Geography, University of Tartu, Vanemuise 46, Tartu 51014, Estonia

${ }^{5}$ College of Civil Aviation, Nanjing University of Aeronautics and Astronautics, Nanjing 210016, China

Direct correspondence to: Christophe Vandeviver, Department of Criminology, Criminal Law and Social Law, Ghent University, Universiteitstraat 4, 9000 Ghent, Belgium.

Email: Christophe.Vandeviver@UGent.be

This work was supported in part by the Ghent University Research Council (UGent-BOF) Interdisciplinary Research Project funding scheme [BOF18/IOP/001 to C.V., T.V.B., F.W.]. Christophe Vandeviver's contribution was supported in part by the Research Foundation Flanders (FWO) Postdoctoral Fellowship funding scheme [12CO619N to C.V.]. Frank Witlox's contribution was supported by the Estonian Research Council [PUT PRG306 501 to F.W.].

The authors declare no conflict of interests.

\section{QUICK MENU:}

INTRODUCTION

METHODS

RESULTS

DISCUSSION 


\title{
Policing Directions: A Systematic Review on the Efficacy of Quantitative Police Presence
}

\begin{abstract}
This systematic review assesses the efficacy of quantitative police presence. The review also investigates concepts of police presence and differences between reported effects. PRISMA (Preferred Reporting Items for Systematic Reviews and Meta-Analyses) guidelines and protocols are used to systematically identify and review eligible studies on police presence. Further, quality assessment and findings synthesis are used to map limitations of current research as well as grounds for future avenues. The systematic search strategies yielded 49 studies focusing on testing the effects of police presence or evaluating its measurement. We find evidence that police presence has mostly positive effects on reducing crimes related to motor theft, property, violence, and guns. Police presence also reduces calls for service and improves traffic behaviour. Police presence focused on specific areas, times, and types of crime achieves maximum efficacy. The reviewed studies show a high degree of heterogeneity in reporting, which limits comparability of findings across studies. Research on police presence presents evidence for crime preventative effects of focused police actions. Police forces can be focused on certain areas, times, and types of crimes. We encourage future research to focus on police presence en route and its effects, including crime prevention, traffic regulation, and fear of crime.
\end{abstract}

Keywords: police presence, deterrence, patrol, crime prevention

\section{Introduction}

Throughout police research scholars agree that police presence matters, especially in preventing crimes (see, Andenæs 1974, Kelling et al. 1974, Pfuhl Jr 1983, Esbensen and Taylor 1984, Armour 1986, Koper 1995, Carrabine 2009, Ming-Jen Lin 2009). Criminological theory has placed police presence at its core. Deterrence theory suggests that criminal activity can be deterred through police presence (Durlauf and Nagin 2011). By elevating either the risk 
(general deterrence) of being caught in the act or the severity (specific deterrence) of punitive action, offenders are deterred from committing a criminal act as the expected costs outweigh expected benefits (see, Durlauf and Nagin 2011, Nagin 2013, Nagin et al. 2015). Thus, police act as a symbol of general deterrence while they enforce the law (e.g., Ming-Jen Lin 2009, Braga et al. 2019a). Cohen and Felson (1979) argued that criminal opportunities arise through routine activities of offenders, victims, and guardians. Crimes can only take place when an offender, a victim and the absence of a 'capable' guardian (e.g., police officers) come together (Cohen and Felson 1979, p. 589, Felson 1986, p. 121). Therefore, police officers need to be at the right place at the right moment to prevent criminal acts. Although different believes on how to optimally deploy police forces exist, all these strategies, such as community policing, broken window policing, pulling-levers policing, or hot spots policing (e.g., Weisburd et al. 2011, Ariel et al. 2016, Braga et al. 2019a, Weisburd and Braga 2019), share the basic assumption that police presence affects social realities. Two questions remain: What social realities can be affected and how much presence is needed to do so?

Concepts of police presence have lacked clarity and neglected the very meaning of presence, in terms of physical presence of police forces (e.g., McPheters and Stronge 1974, Levine 1975, Levitt 2002). Neither police expenditures nor number of officers constitute a measure of physical police presence in the field. We present an incipient definition of police presence:

Police Presence at core is less concerned with performative aspects of policing and patrols (i.e., how they police), but rather focused on the structural characteristics of it (i.e., where and when they police, how many officers are present, how long they are present). It describes social, spatial, and temporal aspects of police work, which can be measured as definite quantities 
This systematic review investigates the state of the art in research on the efficacy of police presence. Thus, we want to know: what are quantitative and qualitative effects of police presence?

\section{Methods}

We conducted a systematic review in accordance to PRISMA guidelines (see Moher et al. 2010). To be eligible for this review, studies had to focus on:

(1) measurable police presence. Suitable studies reported police presence in quantitative measures, e.g., time of police presence, number of visits, hours of officers per police beat, or length of patrol shifts (e.g., Bowers and Hirsch 1987, Kaplan et al. 2000, McGarrell et al. 2001, Zech et al. 2005, Ratcliffe et al. 2011, Taylor et al. 2011, Novak et al. 2016, Stephensen 2017, Ariel et al. 2019, Collazos et al. 2020). This excluded studies that either focused on police expenditures (McPheters and Stronge 1974), police personnel (Levine 1975, Levitt 2002), or tried to infer a level of police presence from law enforcement actions such as arrests rates (Weisburd et al. 2016). These excluded measures do not allow for a precise measurement in specific spatial units, as they cannot distinguish between the proportion of time spent outside or inside police stations $^{1}$

(2) physical police presence defined as a police officer or a (marked) police vehicle, in contrast to alternative ways of police presence such as a picture or cut-out of a police officer (e.g., Simpson et al. 2020)

\footnotetext{
${ }^{1}$ In order to be visible and present, police forces need to be in the "field". For example, the officer-citizen ratio does not give a proper representation of physical police presence.
} 
(3) measures of qualitative (i.e. fear of crime, attitudes towards the police) or quantitative (i.e. reported crime rates, calls for service) effects of police presence or methodological considerations on measuring police presence (Wain and Ariel 2014, Davies and Bowers 2019)

(4) And, due to the authors' language proficiencies, eligible studies were limited to proceedings published in English, Dutch, and German ${ }^{2}$.

\section{Search Strategies and Databases}

Discrete search strategies were deployed to extensively search for relevant literature. First, a keyword search ${ }^{3}$ was conducted on eleven literature databases ${ }^{4}$, with texts and abstract screening $^{5}$. Second, references from reviews that focused on police programs, police practices, and patrol strategies were consulted (Famega 2005, Bradford 2011, Lee et al. 2013, Braga et al. 2014, Braga et al. 2015, Carriaga and Worrall 2015, Braga and Welsh 2016, Lee et al. 2016, Chalfin and McCrary 2017, Braga et al. 2019b, Braga et al. 2019a, Braga et al. 2019c, Kounadi et al. 2020). Third, a cross-reference search was conducted on the preliminary selection to identify relevant publications, which were not yielded during the search (e.g., Thaler 1977, Richards et al. 1985, Draca et al. 2007, Hinkle and Weisburd 2008, Rosenfeld et al. 2014, Blattman et al. 2017, Mitchell 2017). Ultimately, three of the co-authors critically judged the final selection and one of the co-authors validated the deployed search strategies.

\footnotetext{
${ }^{2}$ Searches performed on abstract databases can yield studies written in other languages than the abstract.

3 The search terms were: "Police Presence", "Police Patrol" AND "Presence", "Police Deployment", "Police Visibility", "Hot spots Policing", "Community policing" AND "Presence", "Broken windows policing", "Problem-orientated Policing", "Focused Deterrence", "Patrol"

4 These databases were: Elsevier (Science Direct), Emerald Publishing, JSTOR, National Criminal Justice Reference Service (NCJRS), ProQuest (Criminology Collection), Sabinet, Sage, Springer, Taylor \& Francis, Web of Science, and Wiley

${ }^{5}$ Due to limitations of search hit extraction, on three of the eleven databases abstract searches were performed.
} 
The search was conducted in September 2020. Hence, the review includes studies that were published or available before end of September 2020. The list of variables was derived from examining other research on police and policing (e.g., Sacks 2000, Smith et al. 2005, Pullin and Stewart 2006, Staples and Niazi 2007, Braga and Weisburd 2014, 2015, Depraetere et al. 2020, Dewinter et al. 2020).

In contrast to systematic reviews on policing at large, we have included non-experimental research designs. Randomized controlled trials (RCT) represent the highest standard to evaluate programs and interventions (Kaptchuk 2001). As this systematic review aims at identifying all research directions and conceptualizations of police presence, excluding all studies other than RCT appeared overly restrictive.

\section{Results}

\section{[INSERT FIGURE 1]}

\section{Characteristics of selected Studies}

The systematic database search yielded 118 eligible studies for full-text assessment. We identified 49 eligible studies for this review (see Figure $1^{6}$ ). The majority of identified studies were published after 2013 (53\%), with the oldest study dating back to the early 1970's (Kelling et al. 1974). Since 2011 a rise in the number of studies on police presence can be noticed (see Figure 2).

\footnotetext{
${ }^{6}$ See Table 3 for a complete list of all 49 studies
} 
Most studies analysed police presence in the United States $(n=33)$, the United Kingdom $(n=7)$, Australia $(n=2)$, and Canada $(n=2)$ (see Table $\left.1^{7}\right)$. A predominant number of studies was published as journal articles $(n=43)^{8}$. All eligible studies implemented quantitative research designs. About three quarters of the selected studies implemented experimental research designs $(n=36)$, of which 13 conducted randomized controlled trials (e.g., Sherman et al. 1995b, Sherman et al. 1995a, Ratcliffe et al. 2011, Taylor et al. 2011, Rosenfeld et al. 2014, Barnes et al. 2020). On average police presence was monitored for approximately 350 days (SD 483 days). Equally, sample sizes ${ }^{9}$ differed. Studies document a mean sample size of 282 with a standard deviation of 975 spatial samples. Analyses were conducted on the micro $(\mathrm{n}=30)$, meso $(\mathrm{n}=13)$, and macro $(\mathrm{n}=5)$ level.

\section{[INSERT FIGURE 2]}

The selected body of research comprises different types of policing such as hot spots policing $(\mathrm{n}=20)$, routine patrol $(\mathrm{n}=10)$, or traffic patrol $(\mathrm{n}=8)$. Regardless of deployed strategies, motor patrol $(\mathrm{n}=23)$ (e.g., Kaplan et al. 2000, Medina et al. 2009, Davies and Bowers 2019) and foot patrol $(\mathrm{n}=20)($ e.g., Kelling et al. 1981, Ratcliffe et al. 2011, Sorg et al. 2013) were most commonly evaluated. This comes as no surprise as motor patrol is wide spread (Ariel et al. 2019) and foot patrol manifests the most traditional way of policing (see, Kelling et al. 1974, Carrabine 2009). While crime still being the general focus of analysis $(n=33)$, around one quarter of studies concentrated on calls for service $(n=14)$ and almost a

\footnotetext{
${ }^{7}$ See Table 2 for an overview of all assessed variables

${ }^{8}$ Including one preprint.

${ }^{9}$ Sample size here refers to the number of spatial units that were used to measure police presence
} 
fifth on traffic violations $(n=9)$. A great number of studies attributed positive ${ }^{10}$ effects to police presence $(n=37)$.

All but two studies focused on uniformed or marked police forces $(n=47)$. The number of officers per shift $(\mathrm{n}=13)$ and the dosage (Ariel et al. 2019, Davies and Bowers 2019, Lum et al. 2020) of police presence $(\mathrm{n}=13)$, for example, in minutes per spatial unit were used. Another approach is to determine physical police presence with the number of visits $(n=4)$ officers paid to a certain area or through designated length of police officer shifts $(n=9)$. Around a third of the studies measured police presence through information extracted from police staffing and deployment data $(\mathrm{n}=15)$, followed by GPS (Global Positioning System) $(n=8)$, and officer radio log and call data $(n=6)$. Approximately half of the selected studies used low $(n=17)$ or very low precision $(n=9)$, while a third documented high $(n=15)$ precision measurement ${ }^{11}$. Research on police presence either focused on specific destinations within a jurisdiction $(n=33)$ or the entire jurisdiction $(n=16)$.

\section{[INSERT TABLE 1]}

\section{Focused (on) Crime Deterrence}

Evaluations of police presence focused predominantly on reducing reported crimes ( $\mathrm{n}=33$ ). Apart from four studies (Schnelle et al. 1977, Esbensen and Taylor 1984, Fritsch et

\footnotetext{
${ }^{10}$ Due to the variety of effects examined, we use positive as an indication of desired outcome (i.e., statistical negative effect between police presence and reduction in crime, or statistical positive effect between police presence and trust in the police)

${ }^{11}$ The here introduced categorization goes as follows:

Very low: no mention of measurement, unclear basis for calculations

Low: Staffing schedules, observations, hand written patrol logs

Medium: Deployment data, Radio log and call data

High: GPS tracking, experimental placement
} 
al. 1999, Rosenfeld et al. 2014), all studies state that police presence reduces crime (e.g., Koper 1995, Santos 2013, Rosenfeld et al. 2014, Mitchell 2017, Weisburd et al. 2017). As various hot spots experiments have stated (e.g., Braga et al. 2014, Braga et al. 2019a, Braga et al. 2019b), crime can be reduced through focused police actions (Ratcliffe et al. 2011, Taylor et al. 2011). Focused police strategies aim their efforts at locations that experience elevated levels of crime and often focus on specific crime types (Sorg et al. 2013).

Further, Ariel et al. (2019) pointed out, that reduction effects and their statistical significance depend on the baseline of police levels. Essentially, when area $x$ already receives a high level of police presence in the first place any added police forces will most likely show relatively little effects. Therefore, baseline levels of reported crime and police presence have to be considered before evaluating police actions (Ariel et al. 2019).

Police action does not just work best when focused on target areas but also when focused on certain types of crime. Police presence has particular strong crime reduction effects on motor vehicle theft (Di Tella and Schargrodsky 2004, Collazos et al. 2020, Piza et al. 2020), violent crimes (Ratcliffe et al. 2011, Taylor et al. 2011, Novak et al. 2016), and property crime (Andresen and Lau 2014). Similarly, gun related crimes (Sherman and Rogan 1995, Rosenfeld et al. 2014) and liquor inflictions (Fitterer et al. 2017) experienced substantial reductions.

\section{Length vs. Frequency of Police Presence}

The reviewed studies indicate that length of police visits matters more than frequency (see, Koper 1995, Williams \& Coupe 2017). Koper (1995) provided optimal police stop length of 11 to 15 minutes and showed that police stops have to last for more than ten minutes to generate significant deterrent effect and be shorter than 20 minutes, as added presence does not add additional reduction effects. Williams \& Coupe (2017), further, determined that increasing the 
average stop length by $85 \%$ (from 5.2 to 9.6 minutes) can reduce reported crime by up to 20 $\%$.

Ariel et al. (2019, p. 22) introduced the 'London Underground Paradox' referring to the works of Koper (1995), stating that police forces have a statistically larger effect on crime while there was no police presence recorded. This can be well linked to the extension of the Koper curve (Koper 1995) and residual deterrence. Residual deterrence describes the effects of police presence, e.g., reduction in crime, persist for a certain amount of time even after officers left the place (Stephensen 2017, Williams and Coupe 2017, Barnes et al. 2020). Initial deterrence decay deals with the duration of reduction effects and is interested in how fast deterrent effects decay (Sisiopiku and Patel 1999, Sorg et al. 2013, Novak et al. 2016). Sherman et al. (1995a) analysed police raids and reported that twelve days after the crackdowns crime reduction effects went back to baseline.

\section{Displacement of Crime}

One major concern with increased police presence is the displacement of crime, which describes the transition of reported crime from treatment to neighbouring areas (e.g., Haworth et al., 2013). Criminal activity is not prevented but merely pushed around the corner (Blattman et al. 2017). This has been the case for Sherman et al. (1995a) and Sorg et al. (2013). Both studies hypothesized that crime displacement resulted as a consequence of police actions. Consistent with this finding, Ratcliffe et al. (2011) reported a total of 37 displaced crimes during the Philadelphia foot patrol project. In spite of displaced crimes, the net reduction effect stood at 53 prevented violent crimes (Ratcliffe et al. 2011). Many studies accounted for crime displacement or found no support of this side-effect (e.g., Esbensen and Taylor 1984, Rosenfeld et al. 2014, Ariel et al. 2016, Collazos et al. 2020). 
Contrary to hypotheses of displacement, scholars have argued for spill over effects of police presence in form of diffusion of benefits, positive effects extending into neighbouring areas around the target area (Eck and Weisburd 1995). Piza et al. (2020) demonstrated that motor vehicle thefts decreased in neighbouring areas around the business improvement district in Newark. The 'London Underground Paradox' from Ariel et al. (2019) frames the diffusion of crime reduction effects as an outcome of expected police presence in adjacent police areas. Hence, police presence can generate crime reduction effects outside of treatment areas (Ariel et al. 2019, Piza et al. 2020).

\section{Route and Patrol Choices}

Reviewed studies suggest that officer discretion influences police practices. Davies \& Bowers (2019) analysed police presence and police demand, modelled as the proportion of calls for service per street segment in a street network. Their evaluation attempted to analyse any potential match or mis-match of police resources. Overall, police presence and calls for service were rather balanced across all boroughs in the London Metropolitan area, with slightly higher proportions of police presence than calls for service. For cases of an evident mismatch, two rationales were presented. First, streets that connected a high number of streets, were in close proximity of a police station, and classified as major roads received more police presence. Therefore, these streets function as main routes of police while on patrol or responding to calls for service because of their position in the road network (Davies and Bowers 2019). Second, officer discretion was used to explain different provisions across street segments after controlling for road network characteristics. Davies \& Bowers (2019) suggested that officers directed their presence consciously away from certain places, as they might house some form of undesirable social or environmental condition (e.g., land use, 'no-go' areas, or low collective efficacy). 


\section{Fear of Crime and Feeling of Safety}

The investigation into more qualitative effects of police presence on, for example, citizens' feeling of safety or satisfaction with police services remains at the side lines. Only about $12 \%$ $(n=6)$ of all reviewed studies focus partially on broader themes of safety and public perceptions. In line with publicly held opinion, elevated police levels can lead to a decrease in the feeling of safety (Hinkle and Weisburd 2008, Blattman et al. 2017). However, in many cases no change in the feeling of safety nor fear of crime was detected (Kelling et al. 1974, Kelling et al. 1981, Weisburd et al. 2011). Collazos et al. (2020) reported an increase in the perceived level of safety in crime hot spots for the six-month intervention period. After that, no differences in perception were examined between treatment and control area.

Interestingly, while reporting no changes in police legitimacy, fear of crime, nor in collective efficacy, Weisburd et al. (2011) found a positive association between police interventions and perceived physical disorder (i.e., litter or broken windows). Thus, police presence might present a key factor in the individual perception of increased physical disorder and the priming to experience certain areas as more disorderly (see, Weisburd et al. 2011).

\section{Appearance matters}

Research results suggest that police presence can reduce crime and traffic speeds (Armour 1986, Kaplan et al. 2000, Ariel et al. 2016, Ravani and Wang 2018), even when the presence regards unmanned police vehicles (Kaplan et al. 2000). Armour (1986), Kaplan et al. (2000), and Ravani \& Wang (2018) have reported that effects of police presence are not associated with whether a police vehicle is occupied by an officer or not. The mere presence of a police car seems to suffice as a symbol of law enforcement, especially so in high speed areas such as highways. 
Interestingly, effects of stationary police presence versus mobile police presence have yielded mixed results (see, Richards et al. 1985, Sisiopiku and Patel 1999). Sisiopiku \& Patel (1999) reported that a stationary police vehicle would lead to a short-term speed reduction. However, after passing the vehicle drivers accelerated back to their prior driving speed or above. Thus, the impact on traffic speeds remained little (Sisiopiku and Patel 1999). In contrast, Richards et al. (1985) examined driving speeds at work zones and found that a police traffic controller and a stationary police car could reduce the mean speed by up to $26 \%$ and $22 \%$, respectively. Although direct comparisons were not made for all six test sites, circulating patrol cars were only able to reduce the mean speed up to 5\% (Richards et al. 1985).

As only one study (Ariel et al. 2016) has reported on the uniform style of patrol officers, or the vehicle paint for that matter, no conclusive or comparative results are available for the relationship between officer uniform style or police vehicle colouring and effects of physical police presence. Nevertheless, promising explorations into the significance of flashing lights have been made (Medina et al. 2009, Nakano et al. 2019). Nakano et al. (2019) found that drivers perceived police forces as more noticeable while flashing lights were active. Medina et al. (2009) observed distinct differences between the use of flashing lights and driving behaviour. An enforcement setup of a trailer equipped with activated flashing lights resulted in smaller effects than the deactivated setup. Rather than arguing for a high risk of apprehension, it is hypothesized that activated flashing lights indicate present police forces are already busy with ongoing incidences and thus not available to enforce regulations on other passing vehicles (Medina et al. 2009). 


\section{Tracking and analysing Police Presence}

Myriad approaches and technologies exist to measure police presence: staffing schedules (e.g., Kelling et al. 1974, Fritsch et al. 1999, Andresen and Lau 2014, Ariel et al. 2019), officer radio data (e.g., Kelling et al. 1981, Santos 2013, Rosenfeld et al. 2014, Schaefer et al. 2019), or GPS data (e.g., Ariel et al. 2016, Mitchell 2017, Williams and Coupe 2017, Davies and Bowers 2019). In controlled experimental trials, police presence can be set as an experimental condition and measuring might not be necessary, i.e., when a stationary police car is placed in the test area. This, however, was mostly the case for traffic-orientated research (see, Richards et al. 1985, Zech et al. 2005, Walter et al. 2011, Ravani and Wang 2018).

GPS-based technologies have been confirmed as the most precise option to track and measure police presence, as they can collect positional and temporal information at a high rate (Ariel et al. 2016, Collazos et al. 2020). Trackers can be used in body-worn officer radios (Hutt 2020) or installed in police vehicles as AVL (Automated Vehicle Locators) (Mitchell 2017). The lower the ping ${ }^{12}$, the more precise the tracked geoinformation. Barnes et al. (2020) have been able to track police activity with a ping of nine seconds using smartphones as the tracking device.

Data can be linked to a certain level of spatial abstraction. Research has shown that analyses on the microlevel, i.e. street segments or intersections, yield more conclusive results and detect small spatial changes (e.g., Weisburd et al. 2011, Ariel et al. 2019, Davies and Bowers 2019). This trend also becomes evident throughout research on police presence, as around $60 \%$ of studies in this review focused on microgeographic units. However, depending

\footnotetext{
${ }^{12}$ In the case of GPS tracking, a ping refers to the frequency of contacting satellites and sending positioning signals to the receiver. Thus, a ping of ten seconds means that the GPS tracking device sends GPS coordinates every ten seconds to the receiver.
} 
on the research design and effect of interest, using microlevel units is not always feasible (see, Schnelle et al. 1977, Thaler 1977, Sherman and Rogan 1995, Novak et al. 2016).

The level of police can be determined by measuring the number of officers per shift (see, Thaler 1977, Esbensen and Taylor 1984, Bowers and Hirsch 1987, Fitterer et al. 2017), the shift length of officers in the target areas (e.g., Armour 1986, Weisburd et al. 2011, Sorg et al. 2013) or by the number of minutes spent or visits conducted by police forces (e.g., Ariel et al. 2016, Ariel et al. 2019, Schaefer et al. 2019, Barnes et al. 2020). The level of police presence is dependent on tracking precision. The tracking technology needs to be so precise that detailed information, i.e., minutes spent in location $x$, can be retrieved.

Williams \& Coupe (2017) introduced a distinction between measured presence as patrol minutes versus officer minutes. This presents two important results and considerations. First, the use of police dosage as minutes spent or visits paid constitutes the best practice to measure actual presence. Second, this distinction allows to adjust findings by the number of police officers or vehicles present and addresses a prevalent problem within police research. Many studies did not mention the size of the police units nor gave detailed descriptions of other characteristics (Mehay 1979, Stephensen 2017, Davies and Bowers 2019, Hutt 2020).

Schaefer et al. (2019) and Collazos et al. (2020) reported on initiated measures to enhance officer compliance. Williams \& Coupe (2017) provided evidence that officer compliance was relatively low, for officer minutes and patrol minutes recorded at $90 \%$ and 54\%, respectively. On average, when officers reported back to be engaged in 15-min patrols, they actually just spent 10 minutes on patrol (Williams and Coupe 2017). This constitutes an overall compliance rate for 15 -minute patrols of $67 \%$. Ariel et al. (2016) reported average patrol time per visit to be at $8 \mathrm{~min}$, which constitutes a compliance rate of $53 \%$. 


\section{[INSERT TABLE 3]}

\section{Discussion}

\section{Longer and focused Police Presence}

Police presence is most effective when focused on specific places and specific types of crime, in particular motor vehicle theft, violent crimes, property crime, gun related crimes and liquor infractions (see, Ratcliffe et al. 2011, Taylor et al. 2011, Sorg et al. 2013, Novak et al. 2016, Fitterer et al. 2017). All mentioned crime types have one aspect in common, they are rather easily detectable in public spaces and, thus, more policeable for officer. Further, police actions can be focused on a temporal scale. Deriving from routine activity theory, certain times of the day, or seasons, appear to be more prone to specific criminal activity (e.g., Felson 2002, 2008, Felson and Eckert 2018).

When police forces focus on specific places, times, and crimes, their visits in the target areas have larger effects on crime reduction when they are longer rather than more frequent (Koper 1995, Mitchell 2017, Williams and Coupe 2017). Optimal visits last between 11 and 15 minutes each and deterrent effects of these visits can last up to four days (see Koper 1995, Barnes et al. 2020). Three considerations emerge here. First, officer compliance with given patrol orders can possibly be a great factor in their efficacy, both, on crime and traffic enforcement (see, Davies \& Bowers 2019). Williams \& Coupe (2017) have provided estimates that officers' compliance lies at $67 \%$. Cutting visits by these $33 \%$ might substantially alter police presence efficacy, as ordered police visits of 10 to 15 minutes may result in actual police presence of 6.7 to 10.05 minutes. Thus, optimal visit length, theoretically, can only be achieved when assigning officers with visit lengths of 14.9 to 22.3 minutes. Second, as past research has shown that deterrence effects demonstrate a slow decay in the first four days and will diminish 
after 12 days (Sherman et al. 1995a, Barnes et al. 2020), research and practitioners can learn from this to adapt general deployment patters. One possible aim is to focus police presence on a specific place, time, crime type, and ensure physical presence of 10 to 15 minute per visit. Accounting for slow decays can free police resources and provide departments with more capabilities to respond to incidents or develop more specific policing strategies. Third, questions regarding the reasons why longer visits are more effective than more frequent ones potentially hold pathbreaking insights into policing. For instance, police forces might benefit from a disruptive momentum as their visits suddenly change the current environmental setup and citizens become aware of their presence. After a certain amount of time the police presence might be regarded as inherent to the place and police forces are less consciously recognized.

\section{Characteristics of Presence}

Police presence is influenced by its nuanced characteristics. Evidence was presented that unit size (Armour 1986, Kaplan et al. 2000, Williams and Coupe 2017, Ravani and Wang 2018), use of flashing lights (Medina et al. 2009, Nakano et al. 2019), and vehicle mobility (Richards et al. 1985, Sisiopiku and Patel 1999) influence crime reduction, traffic regulation, or perception effects of police presence. Simpson (2019) and Simpson et al. (2020) found that police cars with a black and white vehicle paint are more positively received than white and blue models and that the placement of an officer 'dummy'13 can reduce traffic speed on busy urban roads. Thus, it is fair to assume that extrinsic details of police presence are an important factor to consider.

Which vehicle colour can produce the greatest deterrent effects or reduce fear of crime most effectively? Will the use of flashing lights and sirens be perceived as an indicator for

\footnotetext{
${ }^{13}$ Simpson et al. (2020) have placed a metal police cut-out or "Constable Scarecrow" to test effects of inanimate police presence.
} 
watchful guardians or busy law enforcers? Should officers drive more slowly through certain areas to enhance their level of presence or remain stationary during their focused visit? The answering of these questions requires more detailed reporting of police actions.

\section{Officer-led Policing}

Officer time is accounted for very little and a proportion of their time remains unassigned (e.g., Kelling et al. 1974, Cordner 1979, Cordner 1981, Famega 2005, Famega et al. 2005). Officer compliance with orders in terms of patrol time appears to be rather low (Williams and Coupe 2017). Patrol and routing decisions seem to lie at the officers' discretion (Davies and Bowers 2019) and officers regard this discretion and freedom to patrol quite highly (Koper et al. 2020). Further, Koper et al. (2020) showed that just 56\% of larger police departments in their nationwide survey use crime analysis regularly. Without proper crime analysis police forces cannot be optimally guided while on patrol. This evidently leaves a margin for subjective bias. We suggest two improvements.

First, practitioners and researchers alike can benefit from using state of the art technology to examine officers' compliance with policing directives. Past research has indicated that not all data types allow to gather information on actual police presence (see, Kelling et al. 1974, Schnelle et al. 1977, Esbensen and Taylor 1984, Fitterer et al. 2017). GPS tracking of police activities allows for precise measurement of presence and utilizing big data analyses can shed new light on traditional assumptions of police work (Williams and Coupe 2017, Davies and Bowers 2019, Barnes et al. 2020). For quite some time now, research has been interested in what officers do and how they patrol (Groff et al. 2015, Wuschke et al. 2018). Making use of precise tracking technology and big data analytics can help researchers to pinpoint effects of different policing styles and enable police departments whether police directives are carried 
out effectively. Several reviews have confirmed the effectiveness of policing strategies, such as hot spots or community policing (see, Braga et al. 2014, Braga and Welsh 2016, Braga et al. 2019b, Braga et al. 2019a). Logically, these strategies have to be implemented as planned to generate effects on crime, disorder, or traffic violations.

Second, as almost half of the larger police departments do not deploy sophisticated crime analysis, the prevalence rate of crime analysis can be assumed to be lower in smaller police departments due to limited resources (see, Koper et al. 2020). Weisburd et al. (2015) have shown that the concentration of crimes differs between larger and smaller cities. While $6 \%$ and $1.6 \%$ of street segments in larger cities caused $50 \%$ and $25 \%$ of all reported crime, respectively, only $3,5 \%$ and $0.7 \%$ did so in smaller cities (Weisburd 2015). It remains important that findings are not blindly adapted across structurally different departments and cities but that police are enabled to conduct local crime analysis in order to focus their resources optimally.

\section{Police en route}

All identified research on police presence concentrated either on evaluations in specific destinations or across entire jurisdictions. The majority $(n=33)$ examined effects of police presence in small destinations such as crime hot spots or busy streets (e.g., Cohen et al. 2003, Ariel et al. 2016, Williams and Coupe 2017, Ravani and Wang 2018, Ariel et al. 2019, Barnes et al. 2020, Collazos et al. 2020). The scope of 'destination-orientated' research is inevitably limited to small proportions of officers' time during shifts. Police officers have to move often between destinations, when they are implementing optimal length visits of around 15 minutes. Ariel et al. (2016) have shown that distances between destinations averaged at $1.6 \mathrm{~km}$ and Barnes et al. (2020) noted average distances of $2.5 \mathrm{~km}$, with a maximum of $5.2 \mathrm{~km}$. Assuming, conservatively, an actual visit length of 15 minutes per destination and a distance of $2 \mathrm{~km}$ at a 
travel speed for foot patrols of $5 \mathrm{~km} / \mathrm{h}$, presence at destinations account for approximately $39 \%$ of the officer time per shift ${ }^{14}$. Thus, the remaining $61 \%$ of officer time is spent travelling between destinations or back to police stations. Although patrol and response are mostly carried out with police vehicles, this proportion presumably will be lower in rural jurisdictions with larger distances between destinations (Schaefer et al. 2019).

It could be relevant to study police efforts by not just looking at what are effects of police presence at destination but en route. This holds leastwise three potential improvements. First, shift time is included in its entirety. Destination-orientated approaches focus on a small fraction of shift time and more general perspectives, i.e. at the police beat or city level, mask differences in the microlevel effects of police presence in particular destinations and in transit. Considering that patrol officer compliance was estimated to be around 53 to $67 \%$, evaluations have so far focused on small windows of officer time. Second, police routes can experience novel research, apart from classic framing of routes as shortest paths between response events (Melo et al. 2006, Reis et al. 2006, Lee et al. 2017, Dewinter et al. 2020, Wu et al. 2020). Perhaps police presence on routes has important effects we do not know anything about yet. Third, encompassing police presence in destinations and en route might facilitate an extension of analysis to look at effects not just in terms of crime reduction but traffic safety, citizen satisfaction with police services, accounts of personal fear of crime and police trust. Thus, a more conclusive picture on the effects of police presence and its optimal allocation can be drawn, for all types of police work.

To achieve the differentiation between time spent in destinations and en route, police presence can be tracked with high precision on the microlevel, i.e., street segments. However, analysing police presence on this level might not always be feasible due to lack of data or small

\footnotetext{
${ }^{14}$ Calculation based on data available from Ariel et al. (2016).
} 
sample sizes (see, Bernasco and Steenbeek 2017). Thus, variables of interest, crimes, calls for service, traffic data, police presence, can be collected at the most detailed level and, if needed, abstracted to an appropriate unit of analysis.

\section{Seeing and being seen}

The greatest limitation of police presence analysis is that solely by looking at the data we cannot decode what police officers are doing in the field. This requires more qualitative empirical research and reconsiderations of integral assumptions of deterrence as well as routine activity theory. Following these theories, potential offenders must recognize police officers and be deterred from conducting crimes or notice the absence of police forces and deem the risk low enough to act (see, Felson and Clarke 1998, Felson 2002, 2008, Durlauf and Nagin 2011, Nagin 2013, Paternoster and Bachman 2013). These perspectives focus strongly on offenders' action and perception of risk. Although one limitation of motor patrol was acknowledged to be the inability to detect crimes due to high travel speeds (see, Schnelle et al. 1977), no research has been identified that investigates into the effects of more proactive officer behaviour in terms of actively detecting criminal activity. Borrowing from Jacobs (1962), police officers can have their and can be our 'eyes on the street'. Research could examine whether police can deter crimes, regulate traffic, or improve citizen perception of safety through the actions they perform or through merely being present.

\section{Limitations}

Although more than ten academic databases were searched, it is possible that information was missed due to the database selection. Further, the keyword selection and thus the entire search was influenced by classic and contemporary terminologies in criminology research. This 
could be one explanation for the high representation of studies that focus on the link between police presence and crime rates $(n=33)$. We encourage future research to explore into more nuanced terminologies of police presence. Due to a lack of consistency in reporting, this systematic review does not include a meta-analysis of effect sizes (Forero et al. 2019).

\section{Recommendations \& Future Avenues}

\section{Practice}

i. Deploy police forces in a focused manner, in terms of area, time, and crime type.

ii. Utilize traditional and novel methods for crime analysis to identify pressing problems within local jurisdictions.

iii. Deploy police resources to generate optimal police dosage of around 15 minutes per visit.

iv. Evaluate departmental compliance with policing and patrolling directives and offer high-quality officer training to make officers capable of acting at their discretion.

\section{Research}

v. Report general information and characteristics of police department and patrol strategies at focus (i.e., unit size, vehicle appearance, use of flashing lights, uniform style, etc.).

vi. Conduct more holistic analyses, to distinguish between officer time or patrol time spent in patrol or service destinations and en route.

vii. Pursue interdisciplinary research to obtain more conclusive results on the effects of police presence and link different types of effects (i.e., crime prevention, traffic regulation, public feeling of safety). 
viii. Reassess and consolidate key performance indicators for police work. Extent the scope beyond crime rates to evaluate success of deployed police actions.

ix. Prompt a public discussion of what the police can and should contribute to society. Do we need tactical crime fighters to ensure public order or prevention-orientated agents to report on and solve social problems?

x. Raise public funding for police forces and set up clearly defined police programs. Ensure that police departments, from small to large, have the resources to conduct the appropriate level of crime analysis to identify local problems and develop evidencebased solutions.

\section{Conclusion}

This systematic review of 49 studies provides evidence that police presence generates positive effects for crime prevention, traffic regulation, and citizens' feeling of safety, when police efforts are focused on specific areas, times, and crime types. To achieve significant impact on crime prevention and extend deterrent effects, requires longer rather than more frequent police visits. Further, compliance with police directives can ensure that police are present in the target areas for the ordered amount of time. We see that effects of police presence are more complex than reported in the past. Both, the appearance of police as well as the type of effect studied are interdependent and require more inter-disciplinary research. Evidencebased research into police presence, with a focus on, both, the locations where they are spending time as well as the routes which connect these locations can draw a clearer picture of what police can do about crime, traffic violations, and public fear of crime. Police presence affects along different dimensions and mapping all of these can improve police practices and policing strategies. 


\section{References}

Andenæs, J., 1974. Punishment and deterrence: University of Michigan Press.

Andresen, M.A. and Lau, K.C.Y., 2014. An evaluation of police foot patrol in Lower Lonsdale, British Columbia. Police Practice and Research, 15 (6), 476-489.

Ariel, B., Sherman, L.W., and Newton, M., 2019. Testing hot-spots police patrols against notreatment controls: Temporal and spatial deterrence effects in the London Underground experiment. Criminology, 8 (8), 1-27.

Ariel, B., Weinborn, C., and Sherman, L.W., 2016. "Soft" policing at hot spots-do police community support officers work? A randomized controlled trial. Journal of Experimental Criminology, 12 (3), 277-317.

Armour, M., 1986. The effect of police presence on urban driving speeds. ITE journal, 56 (2), $40-45$.

Barnes, G.C., et al., 2020. Sweet Spots of Residual Deterrence: A Randomized Crossover Experiment in Minimalist Police Patrol.

Bernasco, W. and Steenbeek, W., 2017. More Places than Crimes: Implications for Evaluating the Law of Crime Concentration at Place. Journal of Quantitative Criminology, 33 (3), 451-467.

Blattman, C., et al., 2017. Pushing crime around the corner? estimating experimental impacts of large-scale security interventions: National Bureau of Economic Research Washington, DC.

Bowers, W.J. and Hirsch, J.H., 1987. The impact of foot patrol staffing on crime and disorder in Boston: An unmet promise. Am. J. Police, 6, 17.

Bradford, B., 2011. Police numbers and crime rates-a rapid evidence review. $H M$ Inspectorate of Constabulary, 1-10. 
Braga, A.A., et al., 2019a. Hot spots policing and crime reduction: an update of an ongoing systematic review and meta-analysis. Journal of Experimental Criminology, 15 (3), 289311.

Braga, A.A., Papachristos, A.V., and Hureau, D.M., 2014. The Effects of Hot Spots Policing on Crime: An Updated Systematic Review and Meta-Analysis. Justice Quarterly, 31 (4), 633-663.

Braga, A.A., Weisburd, D., and Turchan, B., 2019b. Focused deterrence strategies effects on crime: A systematic review. Campbell Systematic Reviews, 15 (3), e1051.

Braga, A.A. and Weisburd, D.L., 2014. Must we settle for less rigorous evaluations in large area-based crime prevention programs? Lessons from a Campbell review of focused deterrence. Journal of Experimental Criminology, 10 (4), 573-597.

Braga, A.A. and Weisburd, D.L., 2015. Focused deterrence and the prevention of violent gun injuries: practice, theoretical principles, and scientific evidence. Annual review of public health, 36, 55-68.

Braga, A.A. and Welsh, B.C., 2016. Broken Windows Policing to Reduce Crime: A Systematic Review. Campbell Systematic Reviews [online], 12 (1), 1-31. Available from: https://onlinelibrary.wiley.com/doi/pdf/10.1002/CL2.158.

Braga, A.A., Welsh, B.C., and Schnell, C., 2015. Can policing disorder reduce crime? A systematic review and meta-analysis. Journal of Research in Crime and Delinquency, 52 (4), 567-588.

Braga, A.A., Welsh, B.C., and Schnell, C., 2019c. Disorder policing to reduce crime: A systematic review. Campbell Systematic Reviews, 15 (3), e1050.

Carrabine, E., 2009. Criminology: A sociological introduction. 2nd ed. London: Routledge.

Carriaga, M.L. and Worrall, J.L., 2015. Police levels and crime: a systematic review and meta-analysis. The police journal, 88 (4), 315-333. 
Chalfin, A. and McCrary, J., 2017. Criminal deterrence: A review of the literature. Journal of Economic Literature, 55 (1), 5-48.

Cohen, J., Gorr, W., and Singh, P., 2003. Estimating intervention effects in varying risk settings: Do police raids reduce illegal drug dealing at nuisance bars? Criminology, 41 (2), $257-292$.

Cohen, L.E. and Felson, M., 1979. Social-Change and Crime Rate Trends - Routine Activity Approach. American Sociological Review, 44 (4), 588-608.

Collazos, D., et al., 2020. Hot spots policing in a high-crime environment: An experimental evaluation in Medellin. Journal of Experimental Criminology, 1-34.

Cordner, G., 1981. While on Routine Patrol: What the Police Do When They're Not Doing Anything. Am. J. Police, 1, 94.

Cordner, G.W., 1979. Police patrol work load studies: A review and critique. Police Stud.: Int'l Rev. Police Dev., 2, 50.

Davies, T. and Bowers, K., 2019. Patterns in the supply and demand of urban policing at the street segment level. Policing and Society, 1-23.

Depraetere, J., et al., 2020. Big Boys Don't Cry: A Critical Interpretive Synthesis of Male Sexual Victimization. Trauma, violence \& abuse, 21 (5), 991-1010.

Dewinter, M., et al. 2020. Analysing the Police Patrol Routing Problem: A Review. ISPRS International Journal of Geo-Information, 9(3), p.157.

Di Tella, R. and Schargrodsky, E., 2004. Do police reduce crime? Estimates using the allocation of police forces after a terrorist attack. American Economic Review, 94 (1), $115-133$.

Draca, M., Machin, S., and Witt, R., 2007. Panic on the Streets of London: Police, Crime and the July 2005 Terror Attacks: Chicago: University of Chicago Press, forthcoming. 
Durlauf, S.N. and Nagin, D.S., 2011. Imprisonment and crime: Can both be reduced? Criminology \& Public Policy, 10 (1), 13-54.

Eck, J. and Weisburd, D., 1995. Crime Places in Crime Theory. Crime and Place: Crime Prevention Studies, 4, 1-33.

Esbensen, F.-A. and Taylor, C.R., 1984. Foot patrol and crime rates. American Journal of Criminal Justice, 8 (2), 184-194.

Famega, C.N., 2005. Variation in officer downtime: a review of the research. Policing: Int'l J. Police Strat. \& Mgmt., 28, 388.

Famega, C.N., Frank, J., and Mazerolle, L., 2005. Managing Police Patrol Time: The Role of Supervisor Directives. Justice Quarterly, 22 (4), 540-559.

Felson, M., 1986. Linking Criminal Choices, Routine Activities, Informal Control, and Criminal Outcomes. In: D.B. Cornish and R.V.G. Clarke, eds. The reasoning criminal: Rational choice perspectives on offending / edited by Derek B. Cornish, Ronald V. Clarke. New York: Springer-Verlag, 119-128.

Felson, M., 2002. Crime and everyday life: Sage.

Felson, M., 2008. Routine activity approach. In: R. Wortley and L. Mazerolle, eds. Environmental Criminology and Crime Analysis: Willan, 70-77.

Felson, M. and Clarke, R.V., 1998. Opportunity makes the thief. Police research series, paper, 98, 1-36.

Felson, M. and Eckert, M., 2018. Introductory criminology: The study of risky situations. New York, London: Routledge.

Fitterer, J.L., Nelson, T.A., and Stockwell, T., 2017. The positive effects of increased foot patrols on the incidence of liquor infractions and assaults in the Granville Street Entertainment Area of Vancouver British Columbia Canada. Applied geography, 87, 97105. 
Forero, D.A., et al., 2019. Ten simple rules for carrying out and writing meta-analyses. PLoS computational biology, 15 (5), e1006922.

Fritsch, E.J., Caeti, T.J., and Taylor, R.W., 1999. Gang suppression through saturation patrol, aggressive curfew, and truancy enforcement: A quasi-experimental test of the Dallas antigang initiative. Crime \& Delinquency, 45 (1), 122-139.

Groff, E.R., et al., 2015.Does what police do at hot spots matter? The Philadelphia Policing Tactics Experiment. Criminology, 53 (1), 23-53.

Hinkle, J.C. and Weisburd, D., 2008. The irony of broken windows policing: A micro-place study of the relationship between disorder, focused police crackdowns and fear of crime. Journal of Criminal justice, 36 (6), 503-512.

Hutt, O.K., 2020. Understanding the deterrent effect of police patrol. UCL (University College London).

Jacobs, J., 1962. The Death and Life of Great American Cities. London: Jonathan Cape.

Kaplan, J.L., et al., 2000. Use of an unmanned police car to reduce traffic speed. Journal of Trauma and Acute Care Surgery, 49 (1), 43-46.

Kaptchuk, T.J., 2001. The double-blind, randomized, placebo-controlled trial: gold standard or golden calf? Journal of clinical epidemiology, 54 (6), 541-549.

Kelling, G.L., et al., 1974. The Kansas City Preventive Patrol Experiment: A Summary Report. Washington: Police Foundation.

Kelling, G.L., et al., 1981. The Newark foot patrol experiment.

Koper, C.S., 1995. Just enough police presence: Reducing crime and disorderly behavior by optimizing patrol time in crime hot spots. Justice Quarterly, 12 (4), 649-672.

Koper, C.S., et al., 2020. Proactive policing in the United States: a national survey. Policing: An International Journal of Police Strategies \& Management. 
Kounadi, O., et al., 2020. A systematic review on spatial crime forecasting. Crime Science, 9 (1), 1-22.

Lee, J.-S., Lee, J., and Hoover, L.T., 2017. What conditions affect police response time? Examining situational and neighborhood factors. Police Quarterly, 20 (1), 61-80.

Lee, Y., Corsaro, N., and Eck, J., eds., 2013. Police Force Size and Crime: A Systematic Review of Research From 1968-2013.

Lee, Y., Eck, J.E., and Corsaro, N., 2016. Conclusions from the history of research into the effects of police force size on crime-1968 through 2013: A historical systematic review. Journal of Experimental Criminology, 12 (3), 431-451.

Levine, J.P., 1975. The ineffectiveness of adding police to prevent crime. Public Policy, 23 (4), 523-545.

Levitt, S.D., 2002. Using electoral cycles in police hiring to estimate the effects of police on crime: Reply. American Economic Review, 92 (4), 1244-1250.

Lum, C., et al., 2020. Examining the Empirical Realities of Proactive Policing Through Systematic Observations and Computer-Aided Dispatch Data. Police Quarterly, 2 (3), 109861111989608.

McGarrell, E.F., et al., 2001. Reducing firearms violence through directed police patrol. Criminology \& Public Policy, 1 (1), 119-148.

McPheters, L.R. and Stronge, W.B., 1974. Law enforcement expenditures and urban crime. National Tax Journal, 633-644.

Medina, J.C., et al., 2009. Downstream Effects of Speed Photo-Radar Enforcement and Other Speed Reduction Treatments on Work Zones. Transportation research record, 2107 (1), 24-33.

Mehay, S.L., 1979. The deterrent effect of urban police services: Further results. The Annals of Regional Science, 13 (1), 66-77. 
Melo, A., Belchior, M., and Furtado, V., 2006. Analysing police patrol routes by simulating the physical reorganization of agents. In: L. Antunes and K. Takadama, eds. International Workshop on Multi-Agent Systems and Agent-Based Simulation: Springer, 99-114.

Ming-Jen Lin, 2009. More police, less crime: Evidence from US state data. International Review of Law and Economics, 29 (2), 73-80.

Mitchell, R.J., 2017. Frequency versus duration of police patrol visits for reducing crime in hot spots: non-experimental findings from the Sacramento hot spots experiment.

Cambridge Journal of Evidence-Based Policing, 1 (1), 22-37.

Moher, D., et al., 2010. Preferred reporting items for systematic reviews and meta-analyses: the PRISMA statement.

Nagin, D.S., 2013. Deterrence in the twenty-first century. Crime and Justice, Vol 43: Why Crime Rates Fall, and Why They Don't, 42 (1), 199-263.

Nagin, D.S., Solow, R.M., and Lum, C., 2015. Deterrence, criminal opportunities, and police. Criminology, 53 (1), 74-100.

Nakano, Y., et al., 2019. Effect of visible presence of policing activities on drivers' vigilance and intention to refrain from non-driving activities: A scenario-based survey of general Japanese drivers. Accident Analysis \& Prevention, 133, 1-9.

Novak, K.J., et al., 2016. The efficacy of foot patrol in violent places. Journal of Experimental Criminology, 12 (3), 465-475.

Paternoster, R. and Bachman, R., 2013. Perceptual Deterrence Theory. In: F.T. Cullen and P. Wilcox, eds. The Oxford handbook of criminological theory. Oxford, UK: Oxford University Press.

Pfuhl Jr, E.H., 1983. Police strikes and conventional crime: A look at the data. Criminology, $21(4), 489-504$. 
Piza, E.L., et al., 2020. Crime control effects of a police substation within a business improvement district: A quasi-experimental synthetic control evaluation. Criminology \& Public Policy, 19 (2), 653-684.

Pullin, A.S. and Stewart, G.B., 2006. Guidelines for systematic review in conservation and environmental management. Conservation biology : the journal of the Society for Conservation Biology, 20 (6), 1647-1656.

Ratcliffe, J.H., et al., 2011. The Philadelphia Foot Patrol Experiment: A Randomized Controlled Trial of Police Patrol Effectiveness in Violent Crime Hotspots. Criminology, 49 (3), 795-831.

Ravani, B. and Wang, C., 2018. Speeding in highway work zone: an evaluation of methods of speed control. Accident Analysis \& Prevention, 113, 202-212.

Reis, D., et al., 2006. GAPatrol: An Evolutionary Multiagent Approach for the Automatic Definition of Hotspots and Patrol Routes. In: J.S. Sichman, H. Coelho, and S.O. Rezende, eds. Advances in artificial intelligence - IBERAMIA-SBIA 2006: 2nd international joint conference: 10th Ibero-American Conference on AI, 18th Brazilian AI Symposium, Ribeirao Preto, Brazil, October 23-27, 2006 ; proceedings / Jaime Simao Sichman, Helder Coelho, Solange Oliveira Rezende (eds.). Berlin: Springer, 118-127.

Richards, S.H., Wunderlich, R.C., and Dudek, C.L., 1985. Field evaluation of work zone speed control techniques. Transportation research record, 1035, 66-78.

Rosenfeld, R., Deckard, M.J., and Blackburn, E., 2014. The effects of directed patrol and self-initiated enforcement on firearm violence: A randomized controlled study of hot spot policing. Criminology, 52 (3), 428-449.

Sacks, S.R., 2000. Optimal spatial deployment of police patrol cars. Social Science Computer Review, 18 (1), 40-55. 
Santos, R.G., 2013. A quasi-experimental test and examination of police effectiveness in residential burglary and theft from vehicle micro-time hot spots. Nova Southeastern University.

Schaefer, B.P., Hughes, T., and Cameron Stelzig, W., 2019. Hot spots across the metropolis: Evaluating hot spots directed patrol at city and suburban locations. Justice Quarterly, 123.

Schnelle, J.F., et al., 1977. Patrol evaluation research: a multiple-baseline analysis of saturation police patrolling during day and night hours. Journal of applied behavior analysis, 10 (1), 33-40.

Sherman, L. W., Rogan, D. P., Edwards, T., Whipple, R., Shreve, D., Witcher, D., Trimble, W., The Street Narcotics Unit, Velke, R., Blumberg, M., Beatty, A., Bridgeforth, C. A., 1995a. Deterrent effects of police raids on crack houses: A randomized, controlled experiment. Justice Quarterly, 12 (4), 755-781.

Sherman, L.W. and Rogan, D.P., 1995. Effects of gun seizures on gun violence:"Hot spots" patrol in Kansas City. Justice Quarterly, 12 (4), 673-693.

Sherman, L.W., Shaw, J.W., and Rogan, D.P., 1995b. The Kansas City Gun Experiment: US Department of Justice, Office of Justice Programs, National Institute of ...

Simpson, R., 2019. Police vehicles as symbols of legitimacy. Journal of Experimental Criminology, 15 (1), 87-101.

Simpson, R., McCutcheon, M., and Lal, D., 2020. Reducing speeding via inanimate police presence: An evaluation of a police-directed field study regarding motorist behavior. Criminology \& Public Policy.

Sisiopiku, V.P. and Patel, H., 1999. Study of the impact of police enforcement on motorists' speeds. Transportation research record, 1693 (1), 31-36. 
Smith, B.W., et al., 2005. Explaining Police Officer Discretionary Activity. Criminal Justice Review, 30 (3), 325-346.

Sorg, E.T., et al., 2013. Foot Patrol in Violent Crime Hot Spots: The Longitudinal Impact of Deterrence and Posttreatment Effects of Displacement. Criminology, 51 (1), 65-101.

Staples, M. and Niazi, M., 2007. Experiences using systematic review guidelines. Journal of Systems and Software, 80(9), 1425-1437. Journal of Systems and Software, 80 (9), 14251437.

Stephensen, R.W., 2017. Cooling Down Crime Hot Spots: Impact of Saturation Patrol on Crime Hot Spots in Las Vegas, Nevada.

Taylor, B., Koper, C.S., and Woods, D.J., 2011. A randomized controlled trial of different policing strategies at hot spots of violent crime. Journal of Experimental Criminology, 7 (2), 149-181.

Thaler, R., 1977. An econometric analysis of property crime: interaction between police and criminals. Journal of Public Economics, 8 (1), 37-51.

Wain, N. and Ariel, B., 2014. Tracking of police patrol. Policing: A Journal of Policy and Practice, 8 (3), 274-283.

Walter, L., Broughton, J., and Knowles, J., 2011. The effects of increased police enforcement along a route in London. Accident Analysis \& Prevention, 43 (3), 1219-1227.

Weisburd, D., et al., 2011. The possible "backfire" effects of hot spots policing: An experimental assessment of impacts on legitimacy, fear and collective efficacy. Journal of Experimental Criminology, 7 (4), 297-320.

Weisburd, D., 2015. The Law of Crime Concentration and the Criminology of Place. Criminology, 53 (2), 133-157.

Weisburd, D., et al., 2016. Do stop, question, and frisk practices deter crime? Evidence at microunits of space and time. Criminology \& Public Policy, 15 (1), 31-56. 
Weisburd, D., et al., 2017. Can hot spots policing reduce crime in urban areas? An agentbased simulation. Criminology, 55 (1), 137-173.

Weisburd, D. and Braga, A.A., 2019. Police innovation: Contrasting perspectives: Cambridge University Press.

Williams, S. and Coupe, T., 2017. Frequency vs. length of hot spots patrols: a randomised controlled trial. Cambridge Journal of Evidence-Based Policing, 1 (1), 5-21.

Wu, C.-K., et al., 2020. A Game Theory Approach for Assessment of Risk and Deployment of Police Patrols in Response to Criminal Activity in San Francisco. Risk Analysis, 40 (3), $534-549$.

Wuschke, K.E., et al., 2018. What do police do and where do they do it? International Journal of Police Science \& Management, 20 (1), 19-27.

Zech, W.C., Mohan, S., and Dmochowski, J., 2005. Evaluation of rumble strips and police presence as speed control measures in highway work zones. Practice Periodical on Structural Design and Construction, 10 (4), 267-275. 
TABLES 
Table 1: Comprised summary of reviewed studies $(n=49)$

\begin{tabular}{llcc}
\hline Characteristics & $\mathrm{N}$ & Percen \\
\hline $\begin{array}{l}\text { Evaluation } \\
\text { country }\end{array}$ & & & \\
& United States & 33 & 67.3 \\
& United Kingdom & 7 & 14.3 \\
& Australia & 2 & 4.1 \\
& Canada & 2 & 4.1 \\
& Colombia & 2 & 4.1 \\
& Other* & 3 & 6.1
\end{tabular}

Publication type

$\begin{array}{lcc}\text { Journal article } & 43 & 87.8 \\ \text { Dissertation/Thesis } & 3 & 6.1 \\ \text { Report } & 2 & 4.1 \\ \text { Book } & 1 & 2.0\end{array}$

Research design

$\begin{array}{lcc}\text { Experimental } & 36 & 73.5 \\ \text { Randomized controlled trial } & 13 & 26.5 \\ \text { Quasi-experimental } & 16 & 32.7 \\ \text { Non-experimental } & 13 & 26.5\end{array}$

Policing type

$\begin{array}{lcc}\text { Hot spots policing } & 20 & 40.8 \\ \text { Routine Patrol } & 10 & 20.4 \\ \text { Traffic Patrol } & 8 & 16.3 \\ \text { Crackdowns } & 4 & 8.2 \\ \text { Other** } & 7 & 14.3\end{array}$

Evaluated effect

$\begin{array}{lcc}\text { Reported crime } & 33 & 67.3 \\ \text { Calls for service } & 14 & 28.6 \\ \text { Traffic violations } & 9 & 18.4 \\ \text { Fear of crime \& security } & 6 & 12.2\end{array}$


*Argentina, Japan,

Theoretical Model

** Broken windows policing, Liquor Patrol, Random Patrol, Saturation

Patrol, Terror Patrol 
Table 2: Detailed summary of reviewed studies $(n=49)$

\section{Characteristics}

Evaluation country
United States

33

United Kingdom

Australia

Canada

Colombia

Other*

Journal article

Dissertation/Thesis

Report

Book

Experimental

Randomized controlled trial

Quasi-experimental

Non-experimental

7

2
67.3

14.3

4.1

4.1

4.1

6.1

87.8

6.1

4.1

2.0

73.5

26.5

32.7

26.5

Days of evaluation

Min.

7

Max.

Mean

SD

Policing type

Hot spots policing

Routine Patrol
20

40.8

10 
Traffic Patrol

8

Crackdowns

Other**

Foot Patrol

Bike Patrol

Motor Patrol

Unknown

Reported crime

33

14

Calls for service

Traffic violations

Fear of crime \& security
16.3

8.2

14.3

40.8

2.0

46.9

26.5

67.3

28.6

18.4

12.2

75.5

20.4

4.1

Zero

2

85.7

Increased

42

4.1

Decreased

2

No difference

5

10.2

Police recognizability

Visible officers

47

95.9

Covert \& Visible officers

Unit of police presence

13 
Dosage

Shift length

Visits

Logged hours

Not measured

Staffing \& deployment

GPS-Tracker

Radio logs \& calls

Experiment condition

CAD

Oberservation

CCTV

Other

very low

low

medium

high

Accuracy of measure

Unit of analysis

Micro

Meso

Macro

Not mentioned

Min.

Max.

Mean

SD

Sample size $(N=49)$
30

13

13

26.5

18.4

8.2

4.1

16.3

8

15

30.6

8

16.3

6

12.2

12.2

6.1

6.1

2.0

14.3

7

16.3

34.7

16.3

32.7

16

61.2

26.5

5

10.2

2.0
1

5,697

282.3

974.5 
*Argentina, Japan, Theoretical Model

** Broken windows policing, Liquor Patrol, Random Patrol, Saturation Patrol, Terror Patrol 
Authors

(sample size, period of

analysis, design)
Country Evaluation Effect Effect direction
Level of Police Measure Presence of Unit of Analysis Accucracy
Type

Police/

Policing of

Population
Andresen \& Lau (2014)

$(N$

Days:

$N E$

Ariel et al. (2016)

$(N=$
Days: $183, E$

Ariel et al. (2019)

$(N=72)$, Days: $365, E$

- Reported Crime

- CfS

$+$

$+\quad$ Shift length

$(N=3)$, Days: $70, N E$

Barnes et al. (2020)

$(N=3,720)$, Days: 248 , Australia$$
E
$$

- Reported Crime

- Crime Harm +
Index
Dosage

Micro

Micro GPS (ping:

(150-mete

Minute) (high)

Destination

polygon)

Micro

(Street slip)

na (very low)

Destination

Foot Patrol/

Hot spots

$10-50 k$

Foot Patrol/

Hot spots

$100-500 \mathrm{k}$

Foot Patrol/ > 5 million Hot spots

Motor Patrol/ Traffic Patrol

$<5000$

Dosage

Micro

(Hot spot square)

GPS (ping: 9

sec) (high)
Bike \& Motor

Patrol/

Hot spots
$1-5$

million 
Blattman et al. (2017) $(N=1)$, Days: $249, E$

Colombia

- Reported Crime

- Crime Risk

$+$

Dosage

Micro

(Street Segments)

GPS (ping: 30

sec) (high)

Destination

Officers per Macro

shift (City)

Micro

- CfS

$+$

$+$

Not measured

Staffing duty

(low), shifts

General

Cohen et al. (2003)

$N E$

Collazos et al. (2020)

$(N=967)$, Days: 200, E

Colombia

- Reported Crime

- Fear of Crime

Dosage

Micro

(Street Segment)

GPS (ping: 30

$\begin{array}{lll}- & 120 & \text { sec) Destination } \\ \text { (high) } & \end{array}$

Motor Patrol/

Hot spots

Unknown/ Crack Down

$100-500 \mathrm{k}$

Davies \& Bowers (2019)

$(N=$ Not $)$, Days: $153, N E$

UK

- CfS

o

o

Dosage

Micro

(Street Segment)

GPS (ping: 15

sec) (high)

General

Motor Patrol/

General Patrol

Not measured

Micro

(Block)

na (very low) Destination

Unknown/

Terror Patro

$>5$ million
$(2004)$
$(N=876)$, Days: $275, E$

Argentina - Reported Crime

Patrol/

$>5$ million

Foot Patrol/

$500 \mathrm{k}-1$

million 
Foot \& Motor

$>5$ million

Esbensen \& Taylor (1984) $(N=3)$, Days: $1,295, E$

USA

Officers per Micro

shift

(Street blocks)

Deployment

Hinkle et al. (2008

USA

- Fear of Crime

Hutt

$(N=5697)$, Days: $60, E$

UK

UK - Reported Crime +
Micro
Shift length
(Grid 250x250m)
Foot Patrol/

General Patrol

$50-100 \mathrm{k}$

Foot Patrol/ Liqour Patrol

Unknown/

General Patrol

$1-5$

million

Unknown/

Crack Down

$100-500 \mathrm{k}$

Foot Patrol/ > 5 million
Hot spots 
Kaplan et al. (2000)

$(N=1)$, Days: 29, E

USA

- Traffic Speed

$+$

$+$

- Reported Crime

'- Fear of Crime

$+$

Dosage

Meso

(Patrol beats)

Deployment

data (medium)

General

- Reported Crime

- Fear of Crime

Shift length

Meso

(Patrol beats)

Staffing duty

(low)

General

$(N=15)$, Days: $365, E$

$$
\text { (1995) }
$$

Koper

$(N=100)$, Days: 365 , USA

$N E$

- Reported Crime

Dosage

\section{Micro}

(Address cluster)

Observation

(low)

Destination

Logged hours

Meso

(Police Beats)

Observation

(low)

General

$(N=5)$, Days: 93, E

Medina et al. (2009)

$(N=4)$, Days: 11, E
USA
Micro
(Work zones)
Motor Patrol/

Traffic Patrol

Foot Patrol/

General Patrol

Motor Patrol/

Routine Patrol

Foot \& Motor

Patrol/

Hot spots

Motor Patrol/

General Patrol

$500 \mathrm{k}-$

million 
$(N=42)$, Days: $180, N E$

Nakano et al. (2019)

$(N=367)$, Days: na, $E$

Japan

- Traffic Behavior +

Novak et al. (2016)

$(N=8)$, Days: $90, E$

USA

$+$

USA

- Reported Crime $\quad+$

Ratcliffe et al. (2011)

$(N=120)$, Days: 60, E

USA

- Reported Crime
Shift length

$+\quad$ Shift length $\quad$ (Street block) (low)

Micro
(Street block)
Micro

Not measured

Micro

(Point at Street)

Not appropiate

Destination

Shift length

Meso

(Police Beats)

Staffing

(low)

duty

Destination

Summons

Officers per Micro

shift

(Street block)
Unknown/

General Patrol

$>5$ million
General

Destination

Motor Patrol/

Hot spots

Foot \& Motor

Patrol/

Traffic Patrol

Foot Patrol/

Hot spots

$100-500 \mathrm{k}$

(directed

patrol)

General

(medium)
Staffing duty Destination
(low)
Foot \& Motor

Patrol/

Saturation

Patrol

Foot Patrol/

Hot spots
$500 \mathrm{k}-$

million

$$
100-500 \mathrm{k}
$$

$1-5$
million 
Ravani \& Wang (2018) $(N=4)$, Days: 11, E

USA

- Traffic Speed

$+$

Not measured

Micro

(Street slip)

Placemen

(high)

Destination

Motor Patrol/

Traffic Patrol

Foot \& Motor

Officers per Micro

shift

(Work zones)

(high)

Radio call data

(medium)

Destination

(Street blocks)

Micro

- Reported Crime +

o

Visits

(Hot spots)

Response $\log$

(very low)

Destination

Unknown/

Hot spots

- Reported Crime

- CfS

$+$

Micro

(Street Block)

Radio call data (medium)

Destination

Unknown/

Hot spots

Motor Patrol/

Officers per Meso

shift

(Patrol Zones)
Staffing
(low)

General
Random Patro

$100-500 \mathrm{k}$ 
Sherman \& Rogan (1995) $(N=2)$, Days: 205, E

Sherman et al. (1995a) (N = 207), Days: 199, E USA

- Reported Crime - CfS

Officers per Micro

shift

(Street block)

na (very low)

Destination

Micro

Dosage

(Address cluster)

Observation
(low)

Destination

$(N=110)$, Days: $365, E$

USA

- CfS

$+$

- Traffic speed +

Not measured

Macro

(Highway slip)

Placemen

(high)

Staffing duty

(low)

(Street blocks)

Shift length$$
\text { (Street blocks) }
$$

- Reported Crime

- CfS
Officers per NA

shift
(Not Mentioned) na (very low)
Motor Patrol/

Hot spots

$100-500 \mathrm{k}$

Unknown/

Crack Down

Foot \& Motor

Patrol/

Hot spots

Motor Patrol/

Traffic Patrol

$50-100 k$

Destination (1)

Foot Patrol/

Crack Down

$1-5$ million

Foot \& Motor

Patrol/

$100-500 \mathrm{k}$ 
Motor Patrol/

Saturation

(Street Block)

Office

er Meso

shift

(Census tracts)

$(N=1)$, Days: $365, N E$

USA - Reported Crime$$
\text { - Traffic Speed + }
$$

Meso

(Street slip)

Destination

Walter et al. $(201$
$(N=1)$, Days: $23, N E$

UK

- Traffic Safety

$+$

Visits

(

- Reported Crime

Officers per Meso

shift (Borough)

Policing

Hot spots
(Street Segments)
Patrol

Problem-

orientated

Policing

Foot Patrol/

Hot spots

GPS (ping:

unknown) Destination

(high)

Calculation

(very low)

General

Observation

(low)

Model

Variable (high)

Destination

Unknown/

Hot spots

Unknown/

Broken

Windows

$500 \mathrm{k}-1$

million

$100-500 \mathrm{k}$

Unknown/

General Patrol

$100-500 \mathrm{k}$

Deployment

Destination

$100-500 \mathrm{k}$ 
Williams \& Coupe

(2017) $(N=7)$, Days: $\mathrm{U}$

$100, E$

Zech et al. (2005)

$(N=2)$, Days: $26, E$

USA

- Traffic Speed

$+$

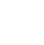

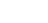

$\begin{array}{ll}\text { Dosage } & \text { Micro } \\ \text { (Hot spot grid) }\end{array}$

unknown)

(medium)

Destination

Destination

Hot spots

$1-5$

million

Officers per Micro (Street slip) Placement

(high)
Motor Patrol/

Traffic Patrol

$+=$ increase, positive, $-=$ decrease, negative, $o=$ no change, no effect 


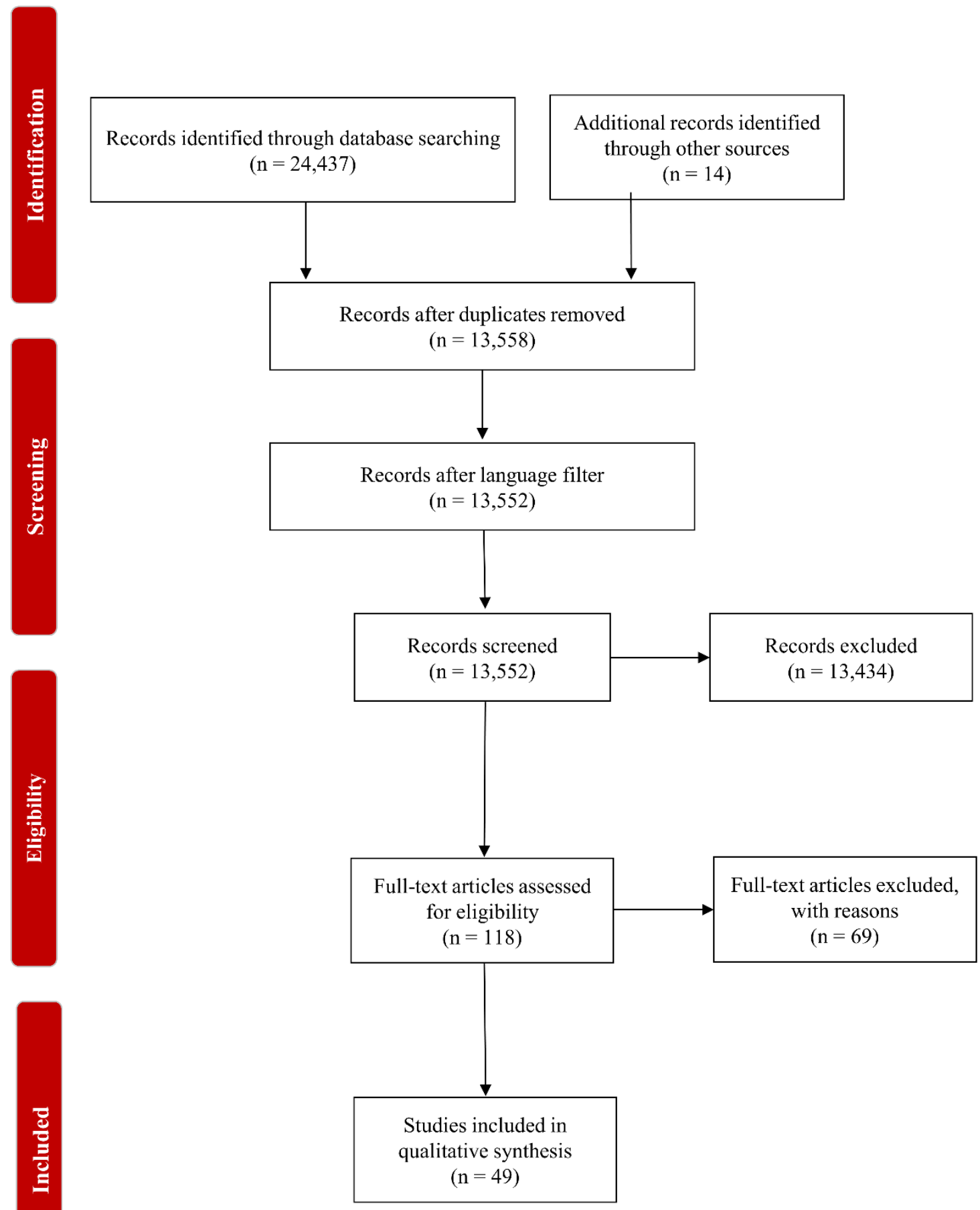

Figure 1: Selection of Studies according to PRISMA Guidelines (see, Moher et al. 2010) 


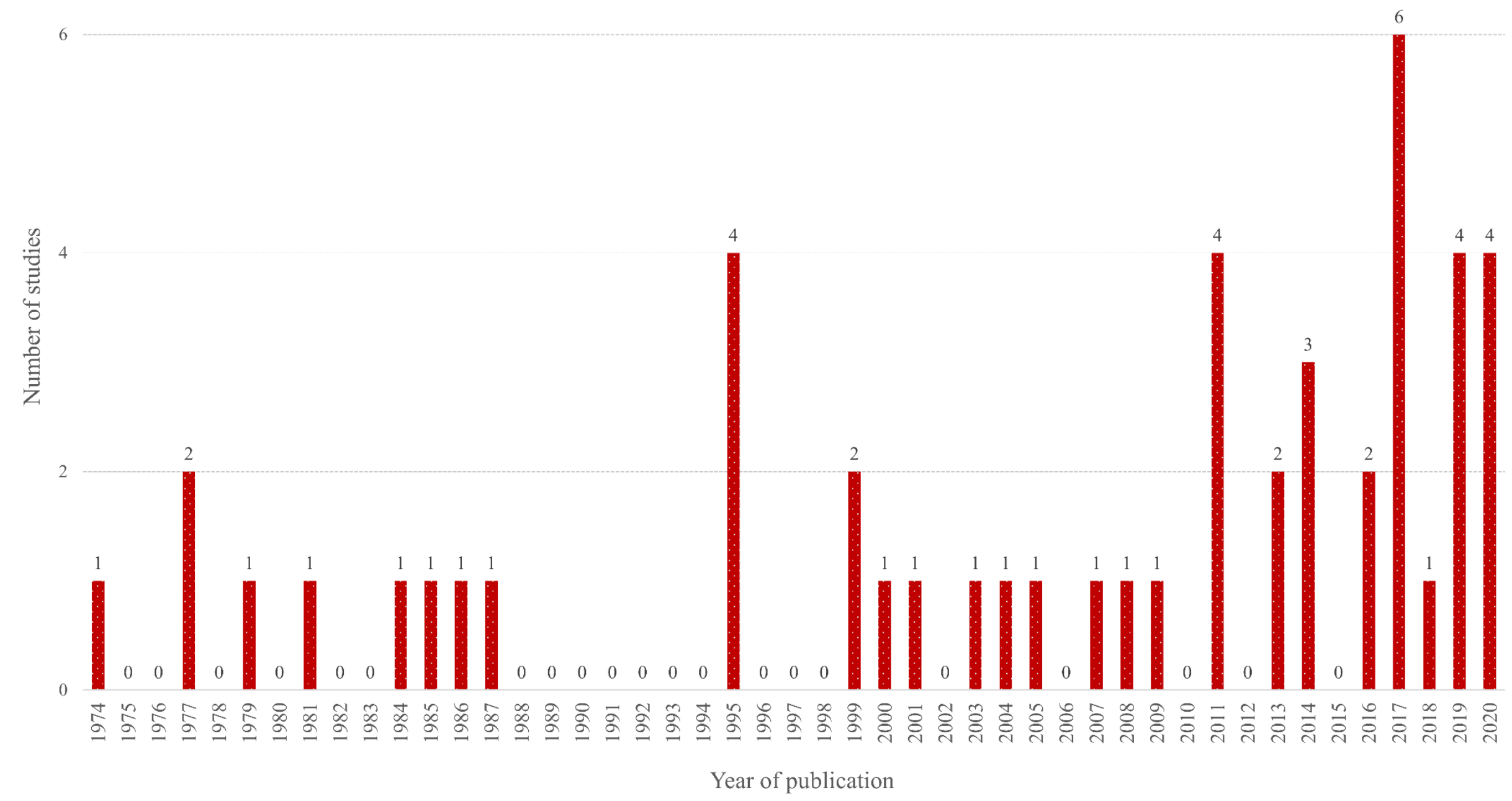

Figure 2: Reviewed Studies by Year of Publication 